\title{
Pattern of ophthalmological accidents and emergencies presenting to hospitals
}

\author{
R S Bhopal, D W Parkin, R F Gillie, K H Han
}

\begin{abstract}
Study objective-To investigate the numbers and characteristics of patients with ophthalmological accidents and emergencies presenting to hospitals.

Design-Prospective survey over eight weeks.

Setting-Two general and one ophthalmic accident and emergency departments, two general outpatient departments, and an eye hospital ward consulting room (all in two teaching hospitals) in Newcastle upon Tyne. Measurements and main resultsConsultation numbers by age, sex, health district of residence, source of referral, diagnosis, and disposal were determined. An average of 37 ophthalmological emergency patients were seen daily. The all cause consultation rate per 1000 population for Newcastle residents was $2 \cdot 64(17 \cdot 2$ per year); for injuries it was $1 \cdot 10(7 \cdot 2$ per year) and for inflammations the rate was 0.91 (5.9 per year). Consultation rates per 1000 were 3.5 for males and 1.8 for females, the excess being explained by the higher risk of injury to men. Most patients were self-referred $(58 \%)$, consulted during office hours $(\mathbf{7 9 . 6 \% )}$, were attended by senior house officers working alone $(83.9 \%)$, and were asked to return for follow up $(66 \cdot 1 \%)$. Patients in an accident and emergency department seldom saw a consultant in their initial management. The diagnoses of patients from outside Newcastle were little different from those who lived within the city. The 10 commonest problems accounted for $68 \%$ of all cases. Injuries were the commonest problem $(40.9 \%$ of all diagnoses).
\end{abstract}

Conclusion-Ophthalmological accident and emergencies are an important component of an accident and emergency department workload. These patients are usually seen by junior doctors, some untrained in ophthalmology. The wide range of presenting problems poses a challenge for training and the organisation of effective referral chains, while the gender difference in injury rates points to the potential for prevention.

F Epidemiol Community Health 1993; 47: 382-387

Acute ophthalmological problems are common, constituting a substantial proportion of the work of general practitioners ${ }^{12}$ and hospital accident and emergency (A\&E) departments. ${ }^{3-7}$ Initial care is provided variously by ophthalmological nurses, ${ }^{56}$ doctors working in specialist clinics, ${ }^{89}$ and doctors in general A\&E departments. ${ }^{1}$ Information on the number of patients, their demographic characteristics, sources of referral, management, and disease patterns is required for informed discussions on health needs and appropriate care. ${ }^{89}$ Table I summarises the main characteristics of the few British studies that provide such information. With the exception of the survey by Sheldrick et $a l^{2}$ previous studies each reported the experience of one centre but did not relate it to a defined population, and hence could not be used to calculate disease rates.

Our survey adds to previous observations in four ways: by comparing ophthalmic and general casualty departments, ${ }^{3}$ by recording information on accident and emergencies which go directly to outpatient clinics or their equivalent, by permitting the calculation of incidence rates for a district health authority, and by providing data on up to three diagnoses, rather than one. The study addresses the following principal questions. How many ophthalmological accidents and emergencies are there and when do they present? What are the age and gender of patients? Where do patients come from? Whom do they consult? What is the pattern of presenting disease?

\section{Data and methods}

SETTING

In Newcastle, ophthalmological services are provided on a subregional basis in two teaching hospitals, the Royal Victoria Infirmary (RVI) and the Newcastle General Hospital (NGH). At the RVI, patients may be seen at the A\&E department by non-specialist staff, or by specialist staff either at the ophthalmology outpatient department or the inpatient ward side-room. A\&E staff and general practitioners both refer patients to the latter.

At the NGH patients may be seen during office hours at an ophthalmic A\&E department or the ophthalmology outpatient department. Out of hours patients are seen at the general $A \& E$ department, where an ophthalmic nurse is usually available, and are often referred for follow up to the ophthalmic A\&E department or ophthalmology outpatient department.

These hospitals draw patients from a wide catchment area with a population of about 1100000 , of which about $25 \%$ resides in the Newcastle Health Authority area. ${ }^{8}$ The nearest alternative specialist facilities in the northern health region are in Sunderland, Darlington, and South Tees. There are no other A\&E departments in Newcastle, the nearest being in Gateshead and North Shields. Newcastle residents would be unlikely to be referred or to refer themselves to 
Table I Characteristics of six studies of ophthalmological accident and emergency services in relation to the present study

\begin{tabular}{|c|c|c|c|c|c|c|c|}
\hline \multirow[b]{2}{*}{ Variable } & \multicolumn{7}{|l|}{ Place } \\
\hline & Bristol $^{6}$ & Leicester ${ }^{7}$ & Southampton ${ }^{5}$ & Canterbury/Kent ${ }^{3}$ & Worcester $^{4}$ & Nottingham $^{2}$ & Newcastle upon Tyne \\
\hline Setting & Eye clinic & Eye clinic & Eye casualty & General casualty & Eye casualty & $\begin{array}{l}7 \text { of } 25 \text { general } \\
\text { practices in } \\
\text { Nottingham and eye } \\
\text { casualty }\end{array}$ & $\begin{array}{l}\text { Eye casualty, eye } \\
\text { clinics, and general } \\
\text { casualty }\end{array}$ \\
\hline Population served & Urban/rural & $\begin{array}{l}\text { Urban/rural } \\
\text { (about } 835000 \text { ) }\end{array}$ & $\begin{array}{l}\text { Urban/rural } \\
\text { (about } 410000 \text { ) }\end{array}$ & Largely rural & $\begin{array}{l}\text { Urban/rural } \\
\text { (about } 240575 \text { ) }\end{array}$ & $\begin{array}{l}\text { Mainly urban } \\
\text { (about } 36018 \text { ) }\end{array}$ & $\begin{array}{l}\text { Urban/rural } \\
\text { (about } 1100000)\end{array}$ \\
\hline Access to service & - & - & Open & Open & Open & Open & $\begin{array}{l}\text { Open to casualties } \\
\text { and by referral to } \\
\text { clinics }\end{array}$ \\
\hline $\begin{array}{l}\text { Consulting } \\
\text { professionals }\end{array}$ & Doctors & Doctors & $\begin{array}{l}\text { Ophthalmic } \\
\text { nurses/doctors }\end{array}$ & Doctors & $\begin{array}{l}\text { Ophthalmic } \\
\text { nurses/doctors }\end{array}$ & $\begin{array}{l}\text { GPs \& eye } \\
\text { casualty staff }\end{array}$ & $\begin{array}{l}\text { Doctors } \\
\text { (few by nurses) }\end{array}$ \\
\hline Timing of study & Feb-July 1981 & $\begin{array}{l}\text { Sept } 1981 \text {-Aug } \\
1982\end{array}$ & Feb-July 1983 & $\begin{array}{l}\text { May 1983-April } \\
1984\end{array}$ & May \& June 1989 & $\begin{array}{l}\text { March 1989-Feb } \\
1990\end{array}$ & April-June 1989 \\
\hline $\begin{array}{l}\text { No. of new } \\
\text { patients or } \\
\text { consultations }\end{array}$ & 7113 & 6576 & 8092 & 1870 & 1629 & $\begin{array}{l}1771 \mathrm{GP} \\
\text { consultations, } 816 \text { eye } \\
\text { casualty consultations }\end{array}$ & 2068 \\
\hline Diagnostic coding & Ad hoc & ICD & Ad hoc & Ad hoc & Ad hoc & Ad hoc & Ad hoc \\
\hline $\begin{array}{l}\text { No. of diagnoses } \\
\text { recorded }\end{array}$ & 1 & 1 & 1 & 1 & 1 & Not stated & 3 \\
\hline
\end{tabular}

hospitals outside the city, though patients who were outside the city at the time of illness may not have consulted doctors in Newcastle.

\section{DEFINITION}

An ophthalmological accident and emergency was defined as "an eye problem, which, in the opinion of patients or their professional advisers, needs immediate (same day) consultation in either an accident and emergency department or an ophthalmology outpatient department". Patients admitted directly as inpatients, that is bypassing outpatient and $A \& E$ departments, were excluded.

\section{DATA COLLECTION}

For eight weeks starting on 10 April 1989, a proforma was completed for every patient. The first part was completed by reception staff and the second by the consulting doctor, except for the diagnostic code which was sometimes entered by one of the research group. These codes were based on an ad hoc disease classification. (Proforma and classification are available from the authors.) Up to three diagnoses could be recorded for each patient. We did not record the cause of the underlying disease, for example the reason for the injury.

The data were analysed using the Statistical Package for the Social Sciences. For calculating diagnosis specific rates (as in table $\mathrm{V}$ ) information on up to three diagnoses was used. Diagnoses were categorised as injury, inflammation, and other. Diagnoses were also grouped as "serious" or "non-serious", based on whether an expert ophthalmological opinion on first presentation would usually be required - for example hyphema, iritis, and cyclitis were in the "serious" category (a full list of "serious" conditions is available from the authors).

The health district of residence was identified from the postcode for 1398 patients, using a computerised postcode directory, and from the town of residence for 487 , using an index of town names and local authority districts. The district was not identified for $183(8.8 \%)$ patients. Districts were further categorised as being in Newcastle Health Authority, surrounding health authorities, more distant health authorities within the Northern Regional Health Authority area, and those outside the northern region. Age, sex, and disease specific rates were calculated for
Newcastle Health Authority using 1988 OPCS population estimates.

\section{Results}

Table II summarises data on the main variables, while table III gives the age and sex specific rates and ratios for the Newcastle Health Authority Area. These data are discussed below in the context of some subgroup analyses (not tabulated).

NUMBER, TIME OF ARRIVAL, AND PLACE OF RESIDENCE OF PATIENTS

There were 2068 new patients-by extrapolation, an estimated 13416 patients per year. Most were seen in the NGH eye casualty department (63.1\%), the NGH A\&E department $(13.6 \%)$, or the RVI A\&E department (19.1\%), and few in outpatient clinics or the hospital ward $(4 \cdot 2 \%)$.

Table II Patients' characteristics

\begin{tabular}{lrr}
\hline Characteristic (no of patients) & No. & $(\%)$ \\
\hline Gender (2061) & & \\
Male & 1385 & $67 \cdot 2$ \\
Female & 676 & $32 \cdot 7$ \\
Age group (2068) (y) & 43 & $2 \cdot 1$ \\
0-4 & 126 & $6 \cdot 1$ \\
5-15 & 1577 & $76 \cdot 3$ \\
16-64 & 322 & $15 \cdot 6$ \\
65+ & 1160 & $58 \cdot 2$ \\
Source of referral (1990) & 409 & $20 \cdot 5$ \\
Self & 107 & $5 \cdot 4$ \\
GP & 227 & $11 \cdot 4$ \\
Hospital & 22 & $1 \cdot 1$ \\
Work/school & 69 & $3 \cdot 5$ \\
Optician & 1000 & $49 \cdot 4$ \\
Other & 610 & $30 \cdot 1$ \\
Time of arrival (2026) (h) & 272 & $13 \cdot 4$ \\
09-12 & 144 & $7 \cdot 1$ \\
13-17 & & \\
18-21 & 913 & $44 \cdot 1$ \\
22-08 & 667 & $32 \cdot 3$ \\
Diagnoses categorised as (2068) & 488 & $23 \cdot 6$ \\
Injury & & \\
Inflammation & 453 & $21 \cdot 9$ \\
Other & 1615 & $78 \cdot 1$ \\
Diagnoses grouped as (2068) & & \\
Serious & 754 & $36 \cdot 7$ \\
Non-serious & 548 & $26 \cdot 7$ \\
Action taken (2054) & 393 & $19 \cdot 1$ \\
Discharged & 58 & $2 \cdot 8$ \\
Asked to return & 301 & $14 \cdot 7$ \\
Referred to outpatients & & \\
Admitted & 1722 & $83 \cdot 9$ \\
Other & 79 & $3 \cdot 8$ \\
Grade of staff seeing patients (n=2052) & 80 & $3 \cdot 9$ \\
Senior house officer (SHO) & 32 & $1 \cdot 6$ \\
SHO and registrar & 73 & $3 \cdot 6$ \\
Registrar or senior registrar & 66 & $3 \cdot 2$ \\
Junior and consultant & & \\
Consultant & & \\
Clinical assistant & & \\
& & \\
\hline & &
\end{tabular}


Table III Consultation rates and ratios by age and sex for Newcastle Health Authority residents

\begin{tabular}{|c|c|c|c|c|c|c|c|c|c|c|}
\hline \multirow[b]{2}{*}{ Age group (y) } & \multicolumn{3}{|l|}{ Males } & \multicolumn{3}{|c|}{ Females } & \multicolumn{2}{|c|}{ Male Female Ratio } & \multicolumn{2}{|c|}{ All cases } \\
\hline & Cases & $\begin{array}{l}\text { Pop } \\
\text { (OOO's) }\end{array}$ & $\begin{array}{l}\text { Rate } \\
1000\end{array}$ & Cases & POP & $\begin{array}{l}\text { Rate } \\
1000\end{array}$ & Ratio & $95^{\circ} \circ C I$ & $\begin{array}{l}\text { Rate } \\
1000\end{array}$ & $\begin{array}{l}\text { Estimated } \\
\text { anmual rate }\end{array}$ \\
\hline $0-4$ & 12 & $7 \cdot 7$ & $1 \cdot 56$ & 10 & $6 \cdot 8$ & 1.47 & $1 \cdot 06$ & $(0.46,2.45)$ & 1.52 & $9 \cdot 86$ \\
\hline $5-9$ & 17 & $8 \cdot 7$ & 1.95 & 4 & $8 \cdot 1$ & 0.49 & 3.96 & $(1.33,11.8)$ & 1.25 & $8 \cdot 13$ \\
\hline $10-14$ & 13 & $7 \cdot 8$ & 1.67 & 5 & $7 \cdot 4$ & 0.68 & $2 \cdot 47$ & $(0.88,6.92)$ & $1 \cdot 18$ & $7 \cdot 70$ \\
\hline $15-19$ & 27 & $10 \cdot 5$ & $2 \cdot 57$ & 22 & $10 \cdot 4$ & $2 \cdot 12$ & 1.22 & $(0.69,2.13)$ & $2 \cdot 34$ & $15 \cdot 24$ \\
\hline $20-24$ & 37 & $13 \cdot 1$ & $2 \cdot 82$ & 24 & $12 \cdot 2$ & 1.97 & 1.44 & $(0 \cdot 86,2 \cdot 40)$ & $2 \cdot 41$ & 15.67 \\
\hline $25-29$ & 54 & $11 \cdot 5$ & $4 \cdot 70$ & 21 & $11 \cdot 2$ & 1.88 & 2.50 & $(1.51,4.14)$ & $3 \cdot 30$ & $21 \cdot 48$ \\
\hline $30-34$ & 41 & $9 \cdot 8$ & $4 \cdot 18$ & 17 & 9.5 & 1.79 & $2 \cdot 34$ & $(1.33,4.11)$ & $3 \cdot 01$ & 19.53 \\
\hline $35-39$ & 47 & $9 \cdot 3$ & $5 \cdot 05$ & 17 & $8 \cdot 8$ & 1.93 & $2 \cdot 62$ & $(1.50,4.55)$ & 3.54 & 22.98 \\
\hline $40-44$ & 41 & $9 \cdot 3$ & $4 \cdot 41$ & 13 & $9 \cdot 0$ & 1.44 & 3.05 & $(1.64,5.69)$ & 2.95 & $19 \cdot 18$ \\
\hline $45-49$ & 42 & $7 \cdot 3$ & 5.75 & 11 & $7 \cdot 1$ & 1.55 & $3 \cdot 71$ & $(1.91,7.21)$ & $3 \cdot 68$ & 23.92 \\
\hline $50-54$ & 29 & $7 \cdot 0$ & $4 \cdot 14$ & 16 & $7 \cdot 3$ & $2 \cdot 19$ & 1.89 & $(1 \cdot 03,3 \cdot 48)$ & $3 \cdot 15$ & $20 \cdot 45$ \\
\hline $55-59$ & 32 & $7 \cdot 0$ & 4.57 & 17 & $7 \cdot 5$ & $2 \cdot 27$ & $2 \cdot 02$ & $(1.12,3.63)$ & $3 \cdot 38$ & 21.97 \\
\hline $60-64$ & 27 & $7 \cdot 0$ & $3 \cdot 86$ & 15 & $7 \cdot 8$ & 1.92 & $2 \cdot 01$ & $(1 \cdot 07,3 \cdot 77)$ & $2 \cdot 84$ & 18.45 \\
\hline $65-69$ & 17 & $6 \cdot 6$ & $2 \cdot 58$ & 16 & $8 \cdot 2$ & 1.95 & 1.32 & $(0.67,2.61)$ & $2 \cdot 23$ & $14 \cdot 49$ \\
\hline $70-74$ & 8 & $4 \cdot 7$ & $1 \cdot 70$ & 11 & $6 \cdot 7$ & 1.64 & 1.04 & $(0.42,2.58)$ & 1.67 & $10 \cdot 83$ \\
\hline $75-79$ & 9 & $3 \cdot 6$ & $2 \cdot 50$ & 15 & $6 \cdot 3$ & $2 \cdot 38$ & 1.05 & $(0 \cdot 46,2 \cdot 40)$ & $2 \cdot 42$ & $15 \cdot 76$ \\
\hline $80-84$ & 8 & 1.9 & $4 \cdot 21$ & 17 & $4 \cdot 5$ & 3.78 & $1 \cdot 11$ & $(0 \cdot 48,2 \cdot 58)$ & 3.91 & $25 \cdot 39$ \\
\hline $85+$ & 10 & $1 \cdot 0$ & $10 \cdot 00$ & 8 & $3 \cdot 5$ & $2 \cdot 29$ & $4 \cdot 38$ & $(1.73,11.1)$ & 4.00 & $26 \cdot 00$ \\
\hline Total & 471 & $133 \cdot 8$ & 3.52 & 259 & $142 \cdot 3$ & 1.82 & 1.93 & $(1.67,2.25)$ & $2 \cdot 64$ & $17 \cdot 19$ \\
\hline
\end{tabular}

Weekly counts of completed forms indicated consistency for the $\mathrm{A} \& \mathrm{E}$ departments and the eye casualty department, but not the other sites where some cases were clearly not recorded. We estimate that about $90(5 \%)$ patients seen at the outpatient clinics were not recorded.

There were more patients on weekdays (daily average $=40$ ) than weekend days (Sunday average $=21$, Saturday average $=25$ ). About one fifth $(20.5 \%)$ of all patients were seen in "unsocial" hours - that is between $6 \mathrm{pm}$ and $9 \mathrm{am}$ (table II). By comparison, $12 \cdot 8 \%$ of patients with conditions in the "serious" group presented during these hours; $14.3 \%$ of patients with inflammations and $26 \%$ of patients with injuries presented between $6 \mathrm{pm}$ and $9 \mathrm{am}$.

Thirty nine per cent of patients were Newcastle Health Authority residents, $50 \%$ came from surrounding districts, $10 \%$ came from distant districts, and less than $1 \%$ came from districts outside the northern health region.

AGE AND SEX DISTRIBUTION OF CASES AND INCIDENCE RATES

The mean age was 41 years (range $0-94$, median 39). Those of working age were most likely to consult, and overall, men were almost twice as likely to consult as women; this gender differential also applied to children. The male excess was seen overwhelmingly in the "injury" category, in which males accounted for $84 \%$ of cases. The age and sex distribution summarised above is reflected in the consultation rates for Newcastle residents, shown in table III and the figure. Overall, there were 2.6 consultations per 1000 population over the study period, an estimated $17 \cdot 2$ per 1000 per year

Older people were more likely to have inflammatory conditions and problems which fell into the "serious" group, while younger patients were more likely to have injuries. For example, those over 60 years formed $20 \cdot 1 \%$ of all patients, $29.6 \%$ of patients with problems in the "serious" group, $27.9 \%$ of those with inflammatory problems, and $4.9 \%$ of those with injuries.

SOURCE OF REFFRRAL, GRADE OF CONSLLTING DOCTOR, AND ARRANGEMENTS FOR REVIEW OF PATIENT

Most patients referred themselves to both the RVI $(77 \cdot 1 \%)$ and $\mathrm{NGH}(73.3 \%) \mathrm{A} \& \mathrm{E}$ departments. At the NGH ophthalmic A\&E department, $51 \%$ of patients were self referred. Overall, self referral accounted for $58.1 \%$ of cases. Other sources of referral were general practitioner $(20 \cdot 5 \%)$, work or school $(11.4 \%)$, and hospitals $(5 \cdot 4 \%)$.

Patients were most likely to see a senior house officer alone $(83.9 \%)$, or a senior house officer with a registrar $(3 \cdot 8 \%)$. At the NGH A\&E, which had the highest rate for out of hours presentation, $97 \cdot 3 \%$ of patients saw a senior house officer alone. There, $96 \%$ of patients in our "scrious" group of conditions were also seen by a senior house officer alone though most of these patients would also have been seen by the ophthalmic nurse.

Only 104 patients $(5 \cdot 1 \%)$ were seen by a consultant, and of these $72(3.5 \%)$ saw only a consultant. There were few $(4(0.6 \%))$ consultations with consultant ophthalmologists in the two A\&E departments; the remaining 68 took place in the other three sites. Twenty two conditions were listed by one of us (Mr R F Gillie) as usually warranting specialist advice (for example, orbital injury, venous obstruction, glaucoma, etc). Altogether $67.8 \%$ of patients (160 of 236 ) with these diagnoses were seen by senior house officers alone. Seventeen $(9 \%)$ of these patients were
Figure Consultation rates by age and sex for Newcastle residents

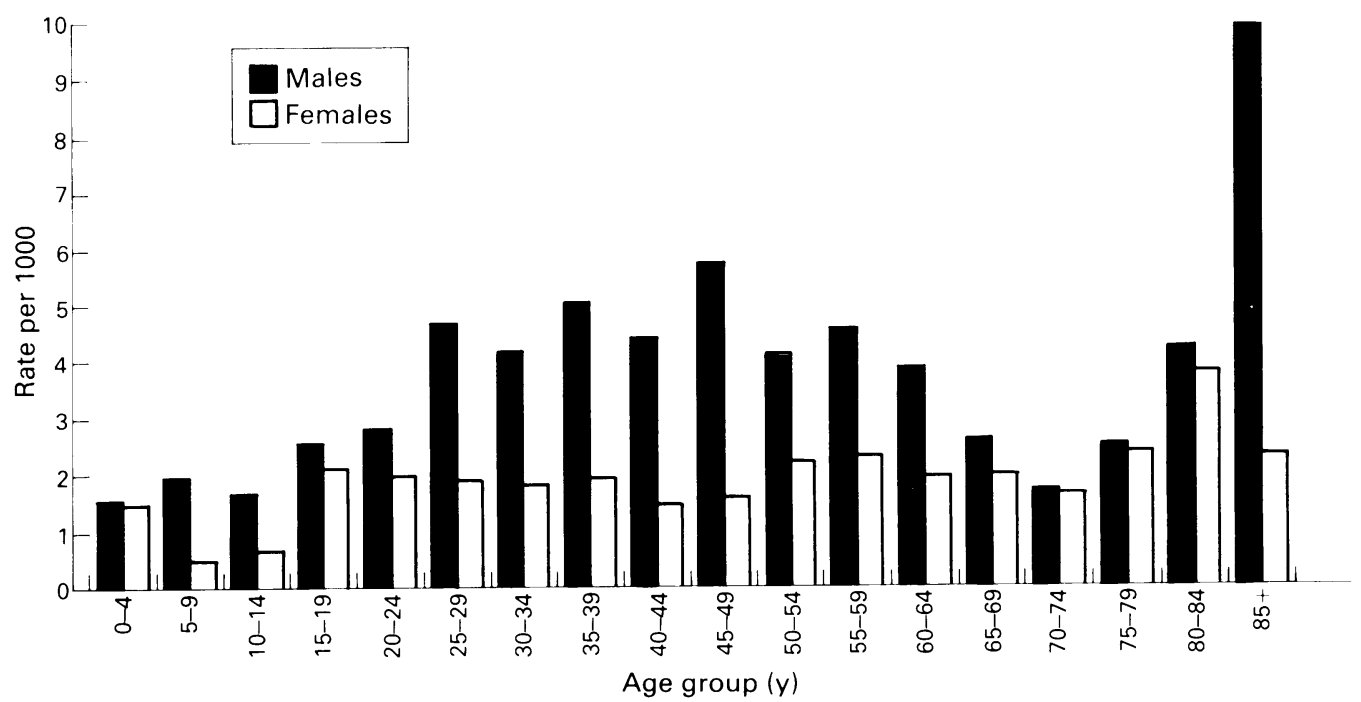


discharged, $14(8 \cdot 2 \%)$ of whom had, on discharge, been seen by a senior house officer alone.

Most patients were either asked to return $(26 \cdot 7 \%)$, referred to outpatients $(19 \cdot 1 \%)$, or were discharged to general practitioner care $(36 \cdot 7 \%)$. Few were admitted to hopsital.

PATTERN OF DISEASE

Table IV shows the diagnostic pattern, arranged anatomically. The 10 commonest diagnoses, which accounted for $68 \%$ of the total, were corneal injury, acute conjunctivitis, superficial keratitis, conjunctival injury, iritis, subconjunctival haemorrhage, lid injury, chronic conjunctivitis, corneal ulcer and tarsal cyst. A total of 163 diagnoses were added by recording more than one diagnosis.

Table $\mathrm{V}$ gives total and gender specific disease rates for selected diagnoses and categories of disease for residents in the Newcastle Health Authority area. The male to female ratio for injuries was $5 \cdot 5: 1$.

Table IV Diagnostic pattem of consultation: anatomical categories

\begin{tabular}{|c|c|c|c|c|c|c|c|c|}
\hline \multirow[b]{2}{*}{ Lids } & \multicolumn{2}{|c|}{$\begin{array}{l}\text { First } \\
\text { diagnosis }(\%)\end{array}$} & \multicolumn{2}{|c|}{$\begin{array}{l}\text { Second } \\
\text { diagnosis }(\%)\end{array}$} & \multicolumn{2}{|c|}{$\begin{array}{l}\text { Third } \\
\text { diagnosis }(\%)\end{array}$} & \multicolumn{2}{|l|}{$\begin{array}{l}\text { Total } \\
\text { no }(\%)\end{array}$} \\
\hline & 183 & $(9 \cdot 0)$ & 11 & $(7 \cdot 6)$ & 3 & $(16 \cdot 7)$ & 197 & $(8 \cdot 8)$ \\
\hline Lacrimal & 15 & $(0.7)$ & 2 & $(1 \cdot 4)$ & 0 & & 17 & $(0 \cdot 8)$ \\
\hline Orbit & 44 & $(2 \cdot 1)$ & 5 & $(3 \cdot 4)$ & 0 & & 49 & $(2 \cdot 2)$ \\
\hline Globe & 24 & $(11 \cdot 6)$ & 6 & $(4 \cdot 1)$ & 0 & & 30 & $(1 \cdot 3)$ \\
\hline Optic nerve & 6 & $(0 \cdot 3)$ & 1 & $(0 \cdot 7)$ & 0 & & 7 & $(0 \cdot 3)$ \\
\hline Motility & 12 & $(0 \cdot 6)$ & 0 & & 0 & & 12 & $(0 \cdot 6)$ \\
\hline \multicolumn{9}{|l|}{ Central nervous } \\
\hline $\begin{array}{l}\text { system (etc } \\
\text { Refractions }\end{array}$ & $\begin{array}{l}32 \\
51\end{array}$ & $\begin{array}{l}(1.5) \\
(2.5)\end{array}$ & 12 & $\begin{array}{l}(8 \cdot 3) \\
(0 \cdot 7)\end{array}$ & $\begin{array}{l}1 \\
2\end{array}$ & $(5 \cdot 6)$ & $\begin{array}{l}45 \\
54\end{array}$ & $\begin{array}{l}(2 \cdot 0) \\
(2 \cdot 4)\end{array}$ \\
\hline Conjunctiva & 489 & $(23$. & 16 & $\begin{array}{l}(0 \cdot 7) \\
(9 \cdot 0)\end{array}$ & $\frac{2}{2}$ & $\begin{array}{l}(11 \cdot 1) \\
(11 \cdot 1)\end{array}$ & 507 & $(22 \cdot 5)$ \\
\hline Cornea & 913 & $(44 \cdot 1)$ & 38 & $(24 \cdot 8)$ & 1 & $(5 \cdot 6)$ & 952 & $(42 \cdot 5)$ \\
\hline \multicolumn{9}{|l|}{ Anterior chamber } \\
\hline Iris & 92 & $(4$. & 10 & $\begin{array}{l}(6.9) \\
(6.9)\end{array}$ & 2 & $\begin{array}{l}(11 \\
(11\end{array}$ & $\begin{array}{r}12 \\
104\end{array}$ & $(4$ \\
\hline Lens & 21 & (i. & 7 & $(4 \cdot 8)$ & 2 & (11. & 30 & $(1 \cdot 3)$ \\
\hline Choroid and retina & 63 & $(3 \cdot 1)$ & 14 & $(9 \cdot 7)$ & 1 & $(5 \cdot 6)$ & 78 & $(3 \cdot 5)$ \\
\hline $\begin{array}{l}\text { Tension } \\
\text { No abnormality }\end{array}$ & 33 & $(1 \cdot 7)$ & 12 & $(8 \cdot 3)$ & 2 & $(11 \cdot 1)$ & 47 & $(2 \cdot 2)$ \\
\hline \multicolumn{2}{|l|}{ No abnormality } & $(0 \cdot 3)$ & - & & - & & & $(0 \cdot 3)$ \\
\hline Missing & 24 & $(1 \cdot 1)$ & & & & & 24 & $(1 \cdot 1)$ \\
\hline Total & 2068 & $(100 \cdot 0)$ & 145 & $(100 \cdot 0)$ & 18 & $(100 \cdot 0)$ & 2231 & $(100 \cdot 0)$ \\
\hline
\end{tabular}

Table $V$ Ophthalmological accidents and emergencies seen in hospitals: rates and ratios for selected diagnoses in Newcastle Health Authority residents (rates per 1000 population)

\begin{tabular}{|c|c|c|c|c|c|}
\hline & $\begin{array}{l}\text { Male } \\
(n=471)\end{array}$ & $\begin{array}{l}\text { Female } \\
(n=259)\end{array}$ & $\begin{array}{l}\text { Total } \\
(n=730)\end{array}$ & $\begin{array}{l}\text { Estimated } \\
\text { annual } \\
\text { rate }\end{array}$ & $\begin{array}{l}\text { M:F } \\
\text { ratio }\end{array}$ \\
\hline \multicolumn{6}{|l|}{ Diagnostic categories } \\
\hline One or more injuries ( 304 ) & 1.91 & $0 \cdot 34$ & $1 \cdot 10$ & $7 \cdot 16$ & $5 \cdot 53$ \\
\hline One or more inflammations (250) & 0.94 & 0.87 & 0.91 & $5 \cdot 89$ & 1.08 \\
\hline \multicolumn{5}{|l|}{$\begin{array}{l}\text { One or more "serious" } \\
\text { conditions }(146)\end{array}$} & $1 \cdot 19$ \\
\hline \multicolumn{6}{|l|}{$\begin{array}{l}\text { Specific diagnoses: } \\
\text { (a) Injuries }\end{array}$} \\
\hline Perforating (1) & 0.01 & $0 \cdot 00$ & 0.00 & $0 \cdot 02$ & - \\
\hline Hyphaema (3) & 0.02 & 0.00 & 0.01 & 0.07 & - \\
\hline Orbital (4) & 0.03 & $0 \cdot 00$ & $0 \cdot 01$ & 0.09 & - \\
\hline Globe (5) & 0.04 & 0.00 & 0.02 & $0 \cdot 12$ & - \\
\hline Lid (16) & $0 \cdot 10$ & $0 \cdot 02$ & 0.06 & $0 \cdot 38$ & $4 \cdot 61$ \\
\hline Conjunctival (43) & $0 \cdot 25$ & 0.07 & $0 \cdot 16$ & 1.01 & 3.51 \\
\hline Corneal $(240)$ & $1 \cdot 52$ & $0 \cdot 25$ & $0 \cdot 87$ & $5 \cdot 65$ & $6 \cdot 03$ \\
\hline \multicolumn{6}{|l|}{ (b) Inflammations } \\
\hline Acute dacryocystitis (3) & 0.01 & 0.01 & 0.01 & 0.07 & 0.53 \\
\hline Episcleritis/scleritis (5) & 0.02 & 0.01 & 0.02 & $0 \cdot 12$ & $1 \cdot 60$ \\
\hline Herpes zoster (5) & 0.00 & $0 \cdot 04$ & $0 \cdot 02$ & $0 \cdot 12$ & $0 \cdot 00$ \\
\hline Allergic conditions of conjunctiva (11) & 0.05 & 0.03 & 0.04 & $0 \cdot 26$ & 1.86 \\
\hline Blepharitis (12) & 0.05 & $0 \cdot 04$ & 0.04 & $0 \cdot 28$ & $1 \cdot 49$ \\
\hline Corneal ulcers (13) & 0.05 & 0.04 & 0.05 & $0 \cdot 31$ & $1 \cdot 24$ \\
\hline Chronic conjunctivitis (16) & 0.04 & $0 \cdot 08$ & 0.06 & $0 \cdot 38$ & $0 \cdot 48$ \\
\hline Entropion \& trichiasis (19) & 0.07 & $0 \cdot 06$ & 0.07 & $0 \cdot 45$ & $1 \cdot 18$ \\
\hline Iritis (25) & 0.09 & $0 \cdot 09$ & 0.09 & 0.59 & 0.98 \\
\hline Superficial keratitis (57) & 0.23 & $0 \cdot 18$ & $0 \cdot 21$ & $1 \cdot 34$ & $1 \cdot 27$ \\
\hline Acute conjunctivitis (87) & 0.32 & $0 \cdot 31$ & $0 \cdot 32$ & $2 \cdot 05$ & $1 \cdot 04$ \\
\hline \multicolumn{6}{|l|}{ (c) Other conditions } \\
\hline Acute closed angle glaucoma (2) & 0.01 & 0.01 & 0.01 & $0 \cdot 05$ & 1.06 \\
\hline Arterial obstruction (4) & 0.01 & 0.02 & $0 \cdot 01$ & 0.09 & 0.35 \\
\hline Secondary glaucoma (4) & 0.01 & 0.01 & $0 \cdot 01$ & $0 \cdot 09$ & 1.06 \\
\hline Chronic glaucoma (5) & 0.01 & 0.03 & 0.02 & $0 \cdot 12$ & $0 \cdot 27$ \\
\hline Venous obstruction (7) & 0.01 & $0 \cdot 04$ & 0.03 & $0 \cdot 16$ & $0 \cdot 43$ \\
\hline
\end{tabular}

CHARACTERISTICS OF PATIENTS WITH INIURY, AND CONDITIONS GROUPED AS "SERIOUS"

Patients with injury, compared with those with other conditions, were more likely to be male $(84.5 \%$ v $53.5 \%)$, younger (mean age $34 v 46$ years), to be referred from work or school $(19 \cdot 3 \%$ $v 5 \cdot 1 \%$ ), and less likely to be referred on to the outpatient department $(5 \cdot 5 \%$ v 29.9\%).

Patients with diagnoses categorised as "serious" were more likely to be referred by a general practitioner $(37 \cdot 6 \% v 15 \cdot 7 \%)$, to be seen by a doctor other than a senior house officer $(25 \cdot 2 \% v$ $13.5 \%)$, and to be admitted to hospital $(8 \cdot 7 \% v$ $1 \cdot 2 \%$ ) than those with other conditions. Therefore, patients with conditions in the "serious" group seem to be managed differently from others.

COMPARISON OF PATIENTS FROM NEWCASTLE, SURROUNDING, AND DISTANT DISTRICT HEALTH AUTHORITIES

Patients from the three geographical areas were similar with regard to time of arrival, grade of doctor seeing patient, and action on discharge. There were three substantive and statistically significant differences. Firstly, fewer patients from distant districts than from Newcastle were children $(3.7 \% v 9 \cdot 8 \%)\left(\chi^{2}=8 \cdot 54, \mathrm{df}=1, \mathrm{p}<0.005\right)$. Secondly, a lower proportion of distant patients than Newcastle patients were self-referrals $(45 \cdot 5 \%$ $v 70.8 \%)\left(x^{2}=55, \mathrm{df}=1, \mathrm{p}<0.001\right)$. Thirdly, patients from distant districts were more likely to have injury ( $51 \%)$ than Newcastle patients $(42 \%)$ $\left(\chi^{2}=4 \cdot 5, \mathrm{df}=1, \mathrm{p}<0 \cdot 05\right)$.

COMPARISON OF TWO MODELS OF CARE AT TWO HOSPITAL SITES

Departments differed in source of referral, grade of staff, arrangements for review, and types of disorders seen. Not unexpectedly, the two general A\&E departments were similar in many respects, notably the dominance of senior house officers in providing the service, the very high proportion of self-referrals and the high proportion of workload concerned with injury.

\section{Discussion}

METHODS

For pragmatic reasons, particularly the number of staff collecting data, the survey needed to be brief. The period 10 April to 5 June 1989 was chosen as a typical two months, ${ }^{3}$ and the maximum reasonable period over which cooperation from local clerical, nursing, and medical staff could be expected. Clearly, extrapolations to estimate annual cases must be cautious, for the pattern may differ in other months.

Our survey missed some patients at the two outpatient departments and the hospital ward. When the throughput of survey patients in relation to all patients is small, and the staff involved are numerous, maintaining continuity of data collection is difficult. The only other study which has given population based incidence estimates ${ }^{2}$ also reported problems of incomplete data.

Coding was straightforward, except for diagnoses. Diagnostic codes were assigned by clinicians who reported that the coding scheme was easy to use. While previous studies reported one 
diagnosis, we recorded three. As 171 diagnoses were added in this way, past studies have slightly underestimated the problem of ophthalmological accidents and emergencies.

\section{INTERPRETATION OF THE RESULTS}

Health services research such as this is intended to help plan local services and appraise the need for and the nature of existing services. It is important to consider critically whether patterns of care are appropriate to population needs. We now assess our findings in the light of those of other researchers, summarised in table VI.

As these surveys show, the workload created by ophthalmological accidents and emergencies is substantial. The consultation rates in tables III and $\mathrm{V}$ offer an opportunity to estimate the workload in given populations by applying the given age and sex specific rates. The annual consultation rates here (overall 17.2) are a little lower than those from Nottingham (22.7) but, given the relatively smal numbers on which they are calculated $(730$ and 816 respectively), the two figures are mutually supporting. The age and sex patterns in the Nottingham and Newcastle studies are similar.

Information on consultation patterns could in time allow for the rational planning of rotas. It is notable that patients with more serious ophthalmological problems in our "serious" group were not, contrary to expectation, more likely to present during unsocial hours. As with a previous report, ${ }^{5}$ we found that out of hours cases were a small proportion of the total, and were mainly injuries.

Most cases were self referred ( $58 \cdot 1 \%$ ), particularly injuries. Three other studies ${ }^{3-5}$ found that nearly $90 \%$ of patients were self referred. Ophthalmological conditions are commonly treated in general practice. In one study only $15 \%$ were referred to hospital, ${ }^{1}$ and in another ${ }^{2}$ about two thirds of consultations were in general practice. It is clear, however, that patients view hospitals as an important source of primary care for such problems, particularly injuries. The pattern of problems seen in general practice and hospital is different. This is illustrated by McDonnell's study, where bacterial conjunctivitis was 10 times commoner than corneal abrasion and foreign body, ${ }^{1}$ while in our study corneal injury was nearly three times as common as acute and chronic conjunctivitis.

The few referrals from optometrists/opticians, confirming other findings, ${ }^{246}$ indicate that their role in the primary care of acute ophthalmological problems is small. Yet their premises are often better equipped for identifying, if not dealing with, simple problems such as foreign bodies (which are best identified using a slit lamp) than general practitioners' surgeries and some general casualty departments.

Referrals from doctors, in contrast to self referrals, were more likely to be to outpatient departments, the ward, or the ophthalmic $A \& E$ department than to the general A\&E departments. Clearly, doctors do distinguish between the need for general hospital advice and ophthalmological hospital advice. Further, professionally referred patients were more likely to be in the "serious" group. Patients were likely to be seen by a senior house officer alone, however, almost irrespective of their place of residence, time of arrival, diagnosis, and referral source. A consultant opinion was rare, except in outpatient clinics or wards, a generalisation supported by other studies. ${ }^{4}$

The service for ophthalmological accidents and emergencies was led by senior house officers, particularly in the two general accident and emergency departments. This may be the most appropriate grade of doctor to provide care but clearly he or she may need ready access to an opinion from a senior colleague or consultant. Few senior house officers, however, saw a patient together with a senior colleague. In our study, discharge to general practitioner care was less likely than in several others (see table VI). The low discharge rates indicate that the doctors did not perceive the presenting problems as minor.

While diagnoses relating to injuries and conjunctivitis predominated, there was an extremely diverse mix of cases at each site. Thus senior house officers, and ophthalmic nurses if appropriate, in $A \& E$ departments must be adept at distinguishing patients with easily diagnosed and minor problems from those with such diagnoses as corneal ulcer, vitreous haemorrhage, iritis, and glaucoma. There is a wide range of problems about which both ophthalmological and general senior house officers need training. If GPs are to provide first line care, further training is likely to be necessary. ${ }^{10}$ Those who have studied the role of ophthalmic nurses in first line care seem satisfied with the service provided. ${ }^{4}$ Medical audit is required, in the face of the diversity nationally and in Newcastle alone, to study the quality of care provided by various models of care. Thought needs to be given to the nature, costs, and effectiveness of training.
Table VI Summary of selected results from five studies of ophthalmological accidents and emergencies

\begin{tabular}{|c|c|c|c|c|c|c|}
\hline \multirow[b]{2}{*}{ Characteristics } & \multicolumn{6}{|l|}{ Place } \\
\hline & Bristol $^{6}$ & Leicester ${ }^{7}$ & Southampton ${ }^{5}$ & $\begin{array}{l}\text { Canterbury/ } \\
\text { Kent }^{3}\end{array}$ & Worcester $^{4}$ & $\begin{array}{l}\text { Newcastle } \\
\text { upon Tyne } \\
\text { (present study) }\end{array}$ \\
\hline $\begin{array}{l}\text { Modal age range (y) } \\
\text { Sex ratio }(M: F)\end{array}$ & $\overline{-}$ & $\begin{array}{r}20-29 \\
2 \cdot 4: 1\end{array}$ & $\overline{\mathrm{M}}>\mathrm{F}$ & $\begin{array}{c}20-29 \\
3: 1\end{array}$ & $20-29$ & $\begin{array}{c}21-30 \\
2: 1\end{array}$ \\
\hline $\begin{array}{l}\text { Estimated No. of new } \\
\text { patients daily } \\
\text { Out of hours }(\%)\end{array}$ & 39 & 19 & $\begin{array}{l}44 \\
18 \cdot 1\end{array}$ & 5 & 27 & $\begin{array}{l}37 \\
20.5\end{array}$ \\
\hline $\begin{array}{l}\text { Referral: } \\
\text { Self } \\
\text { GP }\end{array}$ & $\begin{array}{l}\overline{7} \cdot 3 \\
\text { (GP or optician) }\end{array}$ & $\begin{array}{l}56 \cdot 0 \\
30 \cdot 0\end{array}$ & $\begin{array}{r}89 \cdot 9 \\
7 \cdot 3\end{array}$ & $\begin{array}{l}89 \cdot 7 \\
\mathrm{NS}\end{array}$ & $\begin{array}{r}86 \cdot 8 \\
9 \cdot 2\end{array}$ & $\begin{array}{l}58 \cdot 2 \\
20 \cdot 5\end{array}$ \\
\hline $\begin{array}{r}\text { Optician } \\
\text { Discharged }\end{array}$ & $\begin{array}{l}\text { NS } \\
60 \cdot 0\end{array}$ & $\begin{array}{r}1 \cdot 0 \\
78 \cdot 0\end{array}$ & $\begin{array}{r}0.7 \\
77 \cdot 8\end{array}$ & $\overline{68} \cdot 9$ & $\begin{array}{l}\text { NS } \\
53 \cdot 8\end{array}$ & $\begin{array}{r}1 \cdot 1 \\
36 \cdot 7\end{array}$ \\
\hline $\begin{array}{l}\text { Diagnosis (\%): } \\
\text { Trauma } \\
\text { Inflammation }\end{array}$ & $\begin{array}{l}45 \cdot 0 \\
35 \cdot 0\end{array}$ & $\overline{29} \cdot 0$ & $43 \cdot 6$ & $\begin{array}{l}65 \cdot 6 \\
21 \cdot 7\end{array}$ & - & $\begin{array}{l}44 \cdot 1 \\
32 \cdot 3\end{array}$ \\
\hline
\end{tabular}


Injury, which is a major cause of serious eye disease, including blindness, constitutes a high proportion of the emergency cases presenting to hospital. The fivefold difference in injury rates between men and women is similar to that shown in Nottingham, ${ }^{2}$ a US population study, ${ }^{11}$ and in a study of ocular trauma cases at a hospital. ${ }^{12}$ Interestingly, the injury excess also occurs among children in the age groups $5-14$ years, as is also reported elsewhere. ${ }^{24}$ This excess is not, therefore, solely due to an occupation related risk, but reflects differences in behaviour and social circumstances. This inequality deserves further study. Meanwhile, the use of safety glasses or goggles during activities that can lead to eye injury needs to be more widely emphasised. ${ }^{13}$

In conclusion, this survey portrays a senior house officer led service that provides a mix of primary and secondary care to a large geographical area. Some patients travel from afar to seek a consultation, and many return for review. Patients from distant districts were no more likely to be discharged to general practitioner care than those from Newcastle; clearly geographical considerations do not loom large in the consultation. Among the fundamental policies of the NHS reforms ${ }^{9}$ are that money should follow the patient, and that patients' views on care should be considered. The effect of implementation of policies which might involve the reorganisation of ophthalmological services so that patients travel moderate distances only for a specialist opinion but local services deal with most common problems needs monitoring. Whether such local first line care should be provided by general practitioners, ophthalmic nurses, specially trained hospital junior staff, or general hospital A\&E staff requires wider discussion.

Many nurses, doctors, and clerical staff diverted their energy to help collect the data. Detailed advice or assistance was provided by Professor A L Crombie, $\mathrm{Mr}$ A K Maitra, Dr H G Pledger (who instigated the study), Mr K Stannard, Dr G Sanders, Mr D D Milne, Mr G A Barnes, Mr S White, Mrs P Bignall, Ms J Hastie, Mrs L Ormond, and Ms J Seddon. Mr L Hutchinson patiently and ably prepared the manuscript. The anonymous referee provided helpful comment. Our thanks to all.

1 McDonnell PJ. How do general practitioners manage eye disease in the community? Br F Ophthalmol 1988; 72: 733-6.

2 Sheldrick JH, Vernon SA, Wilson A, Read SJ. Demand incidence and episode rates of ophthalmic disease in incidence and episode rates of ophthalmic dise
defined urban population. BMF 1992; 305: 933-6.

3 Edwards RS. Ophthalmic emergencies in a district general Edwards RS. Ophthalmic emergencies in a district general
hospital casualty department. Br $\mathcal{f}$ Ophthalmol 1987; 71: 938-42.

4 Burton RC. An audit of Worcester Eye Hospital Casualty Burton RC. An audit of Worcester Eye Hospital Casualty
Department. May and June 1989. Worcester: 9. (Available through authors.)

5 Jones NP, Hayward JM, Khaw PT, Claoue CMP, Elkington AR. Function of an ophthalmic "accident and emergency" department: results of a six month survey. $B M F$ 1986; 292 : $188-90$

6 Vernon SA. Analysis of all new cases seen in a busy regional centre ophthalmic casualty department during a 24-week period. F Roy Soc Med 1983; 76: 279-82.

7 Chiapella P, Rosenthal AR. One year in an eye casualty clinic. Br F Ophthalmol 1985; 69: 865-70.

8 Northern Regional Health Authority. Regional strategic plan 1985-1994. Newcastle, Northern Regional Health Authority 1984 .

9 Secretaries of State for England and Wales, Scotland and Northern Ireland. Working for patients. London: HMSO, 1988.

10 Wilson A. The red eye: a general practice survey. $f$ Roy Coll Gen Pract 1987; 37: 62-4

11 Glynn RJ, Seddon JM, Berlin BM. The incidence of eye injuries in New England adults. Arch ophthalmol 1988; 106: $785-789$.

12 Liggett PE, Pince KJ, Barlow W, Ragen M, Ryan S. Ocular trauma in an urban population. Review of 1132 cases. Ophthalmology 1990; 97: 581-4.

13 Banerjee A. Effectiveness of eye protection in the metal working industry. BMF 1990; 301: 645-6. 